\title{
Insights on the $\mathrm{Na}^{+}$ion storage mechanism in hard carbon: Discrimination between the porosity, surface functional groups and defects
}

\author{
Camélia Matei Ghimbeu ${ }^{\mathrm{a}, \mathrm{b}, *}$, Joanna Górka ${ }^{\mathrm{a}}$, Virgine Simone ${ }^{\mathrm{c}, \mathrm{d}}$, Loïc Simonin ${ }^{\mathrm{c}, \mathrm{d}}$, \\ Sébastien Martinet ${ }^{\mathrm{c}, \mathrm{d}}$, Cathie Vix-Guterl ${ }^{\mathrm{a}, \mathrm{b}}$ \\ ${ }^{a}$ Université de Strasbourg, Université de Haute-Alsace, Institut de Science des Matériaux de Mulhouse, CNRS UMR 7361, 15 rue Jean Starcky, 68057 Mulhouse, France \\ ${ }^{\mathrm{b}}$ Réseau sur le Stockage Electrochimique de l'énergie (RS2E), FR CNRS 3459, 33 Rue Saint Leu, 80039 Amiens Cedex, France \\ ${ }^{\mathrm{c}}$ Université Grenoble Alpes, F-38402 Saint Martin d'Hères, France \\ d CEA, LITEN, F38054 Grenoble, France
}

\begin{abstract}
A B S T R A C T
Sodium ion batteries (SIBs) using hard carbon as negative electrode hold the promise of being low cost alternative to lithium ion batteries (LiBs). However, the $\mathrm{Na}^{+}$storage mechanism in hard carbons is not fully understood yet and the attribution of Na storage in the sloping and plateau regions of the sodiation/desodiation curves remains still controversial. The current work employs $\mathrm{N}_{2}, \mathrm{Kr}$ and $\mathrm{CO}_{2}$ gases to correctly assess the changes in hard carbon porosity induced by different pyrolysis temperature of cellulose. The sloping capacity was found to decrease with the decrease of the specific area of ultramicropores measurable only by $\mathrm{CO}_{2}$ adsorption, while the plateau capacity demonstrated an opposite behavior. The high temperature derived carbons $\left(>1400{ }^{\circ} \mathrm{C}\right)$ present no porosity which disqualifies the attribution of plateau region to the adsorption of $\mathrm{Na}^{+}$in the nanopores but rather the insertion between the pseudo-graphitic domains. Temperature programmed desorption coupled with mass spectrometry (TPD-MS) was performed to determine the nature and the quantity of oxygen surface functional groups followed by oxygen chemisorptions to assess the amount of carbon edge defects expressed by active surface area (ASA) values. A decrease in the amount of oxygen groups and active surface area with the increase of the pyrolysis temperature was observed which is accompanied by a decrease of the sloping capacity. These results shed light in the storage mechanisms, the sloping region being ascribed mainly to the interaction of $\mathrm{Na}^{+}$with carbon edge defects and adsorption in the microporosity while the plateau region assigned to the intercalation of $\mathrm{Na}^{+}$in the pseudo-graphitic nanodomains.
\end{abstract}

\section{Introduction}

Growing energy demands as well as high availability of sodium sources are main driving forces for recent rapid development in the area of sodium ion batteries (SIBs), which hold the promise of being low cost alternative to lithium ion batteries (LiBs) for large-scale electric storage applications [1-5]. At early stage of the development of SIBs it was discovered that graphite, extensively used as anode material in LiBs, shows very limited electrochemical performance in SIBs. In place of graphite, hard carbons became most commonly used materials as anodes [1-5], even though they were displaying rather modest capacities, poor cycling stability and initial current efficiency when compared to lithium ion batteries.

Hard carbons are usually prepared by pyrolysis of organic polymers or sugars at high temperatures and their structure can be described as planar hexagonal network of carbon atoms without ordering in the $\mathrm{c}$ direction. The amorphous areas are mixed with more graphitic layers in which strong cross-linking immobilizes and prevents the development of true graphitic structure even at high temperatures. From fundamental and comprehensive studies viewpoint, phenolic resin-derived carbons are very promising for electrochemical Na-storage due to precise control of the carbon's physical and chemical properties [6]. But lately, thanks to a low cost, large producibility and promising performance, hard carbons obtained from wide range of biomass-derived precursors were brought into the spotlight. They include different forms of cellulose, lignin, peanut skins and shells, banana and shaddock peel, wood [7] as well as a bit less obvious choice for carbon precursors such as peat moss and algal blooms [4].

Speaking about material's performance, even though there is a growing number of reports published each year on the subject, the 
sodium insertion mechanism is not fully understood and the relationship between the texture and microstructure of carbon materials and their performance not fully established. Especially, what affects the irreversible capacity loss, low initial Coulombic efficiency and poor rate performances. The initial irreversible capacity loss is usually associated with SEI formation, although it is also suspected that some of $\mathrm{Na}$ ions can be trapped in the graphene edges and defects between the graphene planes [8].

The most used mechanism to describe the sodium storage in hard carbons is the so-called "falling card" model and was proposed by Stevens and Dahn in 2000 [9]. In this model, the sloping part of the galvanostatic curve (1-0.1 V, vs. $\left.\mathrm{Na}^{+} / \mathrm{Na}\right)$ is associated with $\mathrm{Na}^{+}$intercalation between the graphene sheets in turbostatic domains while the low voltage plateau $\left(0.1-0 \mathrm{~V}\right.$, vs. $\left.\mathrm{Na}^{+} / \mathrm{Na}\right)$ is ascribed to the insertion of $\mathrm{Na}^{+}$into the nanocavities or nanopores. In 2012, Cao et al. [10] firstly suggested based on experimental and theoretical approaches that the sloping region is associated to the $\mathrm{Na}^{+}$adsorption while the plateau region ascribed to the $\mathrm{Na}^{+}$insertion between the graphene layers. Similar mechanism was latter on confirmed by Ding et al. [11]. More recently, several other works pointed out that $\mathrm{Na}$ storage mechanisms ascribed by "falling-card" model in these two regions is not straightfull, the sloping region being associated to the $\mathrm{Na}$ binding on carbon vacancies [12] or the plateau region associated to the Na insertion in graphene domains [11-13].

The link between SEI formation and the surface area of the electrode observed at first for LIBs seems to be valid for SIBs as well. The irreversible capacity loss during the first cycle decreases with the decrease of specific surface area $[1,14]$. It should be mentioned that the carbon surface is formed by basal and edge planes and their amount may change depending on the carbon precursors, carbonization treatments or post-treatment modification. The carbon total surface area involves mainly the basal planes and is widely determined in many works by nitrogen physisorption at $77 \mathrm{~K}$ using the BET method. However, it is well known that such gas do not allow to assess the ultramicropores (pores $<0.7 \mathrm{~nm}$ ). Less concerns on the determination of ultramicropores was given for hard carbons that can be achieved by using slightly smaller gas probe molecule such $\mathrm{CO}_{2}$ at a higher temperature $(273 \mathrm{~K})$, conditions favoring the gas diffusion inside the narrowest micropores. Hard carbons characterized by low nitrogen BET surface area give different electrochemical performances and the existence of such small pores may probably explain in some extent the different performances but to our knowledge not yet investigated in detail.

On the other hand, the edge planes include several types of defects (stacking faults, vacancies, dislocations) placed on the prismatic faces and inside the hexagonal network which constitute the so-called active sites or active surface area (ASA). Their amount depends on the carbon crystallite size/orientation, structural order and vacancy/impurity concentration [15-17] and can be quantified by the amount of oxygen surface complexes formed by oxygen chemisorptions at $300{ }^{\circ} \mathrm{C}$ followed by quantification of formed $\mathrm{CO}$ and $\mathrm{CO}_{2}$ groups using temperature programmed desorption coupled with mass spectrometry (TPD-MS) [15-18]. It has been shown that these active sites induce different reactivity of carbon with gases and electrolytes. Particularly, we have highlighted in several works that the ASA is an important parameter governing the irreversible capacity of graphite in lithium ion batteries [19-21]. More recently we have demonstrated that the active sites are involved in the mechanism of electrochemical double layer supercapacitor formation leading to the improvement of the capacitance in aqueous and organic electrolytes [22].

However, no works linking the carbon defects amount (ASA) with electrochemical performances of Na-ion batteries are published. It is worth to note the work of Bommier et al. [13] where a relationship between the slope capacity and the defects estimated as the ratio $I_{D} / I_{G}$ from Raman Spectroscopy was established. The defect determination by Raman can be linked in some extent to ASA as demonstrated by VixGuterl et al. [18], however, the Raman is not sensitive to the defects induced by the presence of micropores $<2 \mathrm{~nm}$ [23]. Theoretical studies pointed out recently the importance of graphene defects in the interaction with $\mathrm{Na}^{+}[24,25]$.

Later on, it was discovered that not only specific surface area of the electrode material could be entirely responsible for irreversible capacity but also the amount of functional groups on carbon's surface could play significant role. The reactivity and electronic conductivity of carbon surface can also be modified by introducing $\mathrm{N}$ - and O-containing functionalities. This approach turned out to be very beneficial to improve the electrochemical performance of SIBs as well as doping with heteroatoms such as boron, phosphorus and fluorine [26-29].

As one can see from the discussion above, porosity, surface chemistry and defects of hard carbons are key factors affecting their electrochemical performance. Since there is a lack of systematic studies addressing this issue, the goal of this work is to investigate and establish clear relationships between the materials porosity, structure and chemistry and their electrochemical capacity in the sloping and plateau regions. Different gas probing molecules $\left(\mathrm{N}_{2}, \mathrm{CO}_{2}\right.$ and $\left.\mathrm{Kr}\right)$ were used to correctly asses the hard carbon porosity while the surface chemistry and the amount of defects were determined by TPD-MS. An overall picture of the evolution of the sloping and plateau capacities with the microporosity, amount of functional groups, amount of defects and the interlayer spacing is drawn as a function of hard carbon pyrolysis temperature.

\section{Experimental}

\subsection{Hard carbon synthesis/modification}

Several hard carbon samples were prepared by two steps pyrolysis of cellulose (Aldrich, microcrystalline powder) according to our previous work [14]. Both heat treatments were performed under argon atmosphere in a horizontal tube furnace. In the first step, the temperature was increased to $200{ }^{\circ} \mathrm{C}$ using a fast heating rate $\left(20{ }^{\circ} \mathrm{C} / \mathrm{min}\right)$ followed by slow heating rate $\left(1{ }^{\circ} \mathrm{C} / \mathrm{min}\right)$ up to $450{ }^{\circ} \mathrm{C}$ then were cooled down to room temperature. In the second step, the as-prepared materials were pyrolysed to the final temperature $\left(3.33^{\circ} \mathrm{C} / \mathrm{min}\right)$, maintained for $1 \mathrm{~h}$ and cooled down then to room temperature. The six different samples were synthesized using temperatures between $1000{ }^{\circ} \mathrm{C}$ and $1600{ }^{\circ} \mathrm{C}$ and they are labeled as HC-T, where T denotes the annealing temperature (Table 1 ).

To increase the amount of oxygenated groups, the HC-1400 carbon was modified with concentrated nitric acid $\left(\mathrm{HNO}_{3}\right)$. A certain amount of carbon $(\sim 2 \mathrm{~g})$ was immersed in $40 \mathrm{~mL}$ of $\mathrm{HNO}_{3}$ and heated under reflux at $60{ }^{\circ} \mathrm{C}$ for $1 \mathrm{~h}$. After cooling down, the solution containing the carbon was filtered and the recovered carbon washed with plenty distillate water followed by drying at $80{ }^{\circ} \mathrm{C}$. The resulting oxidized material was denoted HC-1400ox. Half of the HC-1400ox oxidized carbon was heat treated further up to $900{ }^{\circ} \mathrm{C}$ under hydrogen in order remove the oxygen functional groups. The resulting reduced carbon was named HC-1400red.

Table 1

Hard carbon characteristics including specific surface area determined by several gases, d-o02 space obtained by XRD patterns, $\mathrm{CO}_{\mathrm{x}}$ desorbed quantities and ASA determined by TPD-MS.

\begin{tabular}{|c|c|c|c|c|c|c|c|}
\hline Sample & $\begin{array}{l}\mathrm{BET}_{\mathrm{N} 2} \\
\mathrm{~m}^{2} / \mathrm{g}\end{array}$ & $\begin{array}{l}\mathrm{BET}_{\mathrm{Kr}} \\
\mathrm{m}^{2} / \mathrm{g}\end{array}$ & $\begin{array}{l}\mathrm{BET}_{\mathrm{CO} 2} \\
\mathrm{~m}^{2} / \mathrm{g}\end{array}$ & $\begin{array}{l}\mathrm{V}_{\text {micro } \mathrm{CO} 2} \\
\mathrm{~cm}^{3} / \mathrm{g}\end{array}$ & $\mathrm{d}_{\text {002-space }} \AA$ & $\begin{array}{l}\mathrm{CO}_{\mathrm{x}} \\
\mathrm{mmol} / \mathrm{g}\end{array}$ & $\begin{array}{l}\text { ASA } \\
\mathrm{m}^{2} / \mathrm{g}\end{array}$ \\
\hline HC- 1000 & 83 & 1.74 & 406 & 0.21 & 3.885 & 0.58 & 44 \\
\hline HC- 1150 & 15 & 1.83 & 380 & 0.18 & 3.834 & 0.33 & 20 \\
\hline HC- 1300 & 6 & 1.93 & 255 & 0.13 & 3.827 & 0.26 & 12 \\
\hline HC- 1400 & 5 & 1.91 & 40 & 0.02 & 3.730 & 0.20 & 7 \\
\hline HC-1600 & 8 & 1.86 & 3 & 0.006 & 3.720 & 0.014 & 1 \\
\hline
\end{tabular}




\subsection{Characterization methods}

Nitrogen, $\mathrm{Kr}$ and $\mathrm{CO}_{2}$ adsorption isotherms were measured on ASAP2020 porosity analyzer from Micromeritics at $77 \mathrm{~K}\left(\mathrm{~N}_{2}\right.$ and $\mathrm{Kr}$ ) and $273 \mathrm{~K}\left(\mathrm{CO}_{2}\right)$. Prior to the analysis, the materials were outgassed under primary vacuum at $300{ }^{\circ} \mathrm{C}$ during one night. The BET specific surface area $S_{B E T}$ was calculated in the relative pressure range, $\mathrm{P} / \mathrm{P}_{0}$ of $0.05-0.3$. The micropore pore size distributions (PSD) were determined from the adsorption branch of isotherms using the 2D NLDFT heterogeneous surface model for carbon materials for $\mathrm{N}_{2}$ and $\mathrm{CO}_{2}$ gases implemented in SAIEUS (Micromeritics) [30,31]. X-ray diffraction analysis was performed with a powder diffractometer D8 ADVANCE A25 from Bruker in Bragg-Brentano reflexion geometry $\theta-\theta$. The diffractometer is equipped with a LynxEye XE-T high resolution energy dispersive 1-D detector $\left(\mathrm{Cu} \mathrm{Ka}{ }_{1}, 2\right)$, leading to ultra fast $\mathrm{X}$-ray diffraction measurements. Transmission electron microscopy (TEM) was used to observe the structure of each sample. TEM images were acquired using a JOEL ARM-200F microscope with working voltage of $200 \mathrm{kV}$.

The surface functionality of hard carbon was analyzed by temperature programmed desorption coupled with mass spectrometry. The material is heat-treated in vacuum with a heating rate of $5{ }^{\circ} \mathrm{C} / \mathrm{min}$ up to $950{ }^{\circ} \mathrm{C}$. The oxygen functional groups are decomposing in $\mathrm{CO}$ and $\mathrm{CO}_{2}$ during the heating process and are continuously quantitatively detected by a mass spectrometer. Water and $\mathrm{H}_{2}$ are evolved as well from the material. Before experiments, the mass spectrometer was calibrated using $\mathrm{N}_{2}(m / z=28), \mathrm{H}_{2}(m / z=2), \mathrm{CO}(m / z=28), \mathrm{CO}_{2}(m / z=44)$ and $\mathrm{H}_{2} \mathrm{O}(\mathrm{m} / z=18)$. The total amount of each gas released was computed by time integration of the TPD curves. The active surface area (ASA) was determined as described in the literature [20]. In summary, the hard-carbon surface is cleaned in a first step by outgassing at $950{ }^{\circ} \mathrm{C}$ for $30 \mathrm{~min}$ under high vacuum $\left(10^{-4} \mathrm{~Pa}\right)$. In a second step, the hard carbon surface is exposed to di-oxygen atmosphere at $300{ }^{\circ} \mathrm{C}$ (di-oxygen pressure: $66.5 \mathrm{~Pa}$ ) during $10 \mathrm{~h}$ allowing the carbon defects to react and to form surface oxygen complexes. After the removal of di-oxygen, the sample is heat-treated up to $950{ }^{\circ} \mathrm{C}$ and the oxygenated complexes formed are decomposed into $\mathrm{CO}$ and $\mathrm{CO}_{2}$ and their amount is quantitatively determined subsequently by mass spectrometry. The surface area occupied by the chemisorbed oxygen (ASA) can be calculated by taking into account the number of mole for each gas desorbed and considering the area of an edge carbon site that chemisorbs an oxygen atom as $0.083 \mathrm{~nm}^{2}[20]$.

\subsection{Electrochemical tests}

Electrode slurries were prepared with the formulation $80 \mathrm{wt} \%$ hard carbon, $10 \mathrm{wt} \%$ Carbon black (super C45 from Timcal-Imerys) and $10 \mathrm{wt} \%$ PVDF (1015 from Solvay) in $N$-methyl pyrrolidone (NMP) solvent. Slurries were coated onto aluminium foils and dried overnight at $55{ }^{\circ} \mathrm{C}$. The 2-electrode coin cells were assembled in an argon filled glovebox. A Celgard 2400 polyethylene separator was put between both electrodes with a Viledon ${ }^{\circledR}$ membrane used as an electrolyte reservoir. Sodium metal (Aldrich, 99.9\%) was used as a counter electrode. The electrolyte was a $1 \mathrm{M}$ solution of $\mathrm{NaPF}_{6}$ (Stella Chemifa, min $98 \%$ pure) in ethylene carbonate/dimethyl carbonate (EC/DMC-UBE America Inc.-ratio $1 / 1$ in volume). The amounts of water and $\mathrm{HF}$ in the electrolyte were measured at laboratory to be less than $30 \mathrm{ppm}$. The electrochemical tests were carried out using an Arbin BT2000 battery cycler. The electrodes were tested upon cycling with a constant current corresponding to a $C / 10$ rate $(37.2 \mathrm{~mA} / \mathrm{g})$ followed by a constant voltage of $10 \mathrm{mV}$ at the end of discharge step only (i.e. sodium uptake).

\section{Results and discussion}

As highlighted in the introduction, the porosity of hard carbons is an important parameter that influences the battery performance, particularly the first irreversible capacity. Usually, the most employed probe molecule to evaluate the textural properties of hard carbons is the nitrogen. However, the nitrogen gas cannot correctly asses the entire porosity of very low surface area materials and in such case $\mathrm{Kr}$ adsorbate is recommended. In addition, the very small pores, called ultramicropores $(<0.7 \mathrm{~nm})$ cannot be as well determined by nitrogen and in this case $\mathrm{CO}_{2}$ is considered the most appropriate in this aim [32]. Such small pores may contribute to the $\mathrm{Na}^{+}$storage mechanism and often not taken into consideration in most of the works. The majority of hard carbon present low surface area when determined by nitrogen adsorption, but information about the ultramicropores are not provided to better compare the materials issued from different precursors and synthesis procedures. Therefore, to completely asses the porosity of hard carbon in this work, $\mathrm{N}_{2}, \mathrm{Kr}$ and $\mathrm{CO}_{2}$ adsorption was performed. The nitrogen adsorption/desorption isotherms at $77 \mathrm{~K}$ were firstly measured and except the sample treated at $1000{ }^{\circ} \mathrm{C}$ (HC-1000) which present a nitrogen surface area of $\sim 80 \mathrm{~m}^{2} / \mathrm{g}$, the thermal treatments at higher temperatures yielded in very low surface area carbon materials (Table 1). As expected, the whole series of samples follows the trend of gradual lowering of BET surface area as the temperature of thermal treatment increases, with quite abrupt drop when temperature exceeds $1000{ }^{\circ} \mathrm{C}$ (Table 1) $[1,6,14,33]$.

The nitrogen adsorption measurements revealed that most of the carbons treated at high temperature in the series possess low surface area close to the detection limit of the technique and because of that they are not distinct enough to differentiate between samples. That is why using probe molecules with different sizes, shapes and different saturation pressures was behind the idea of performing $\mathrm{Kr}$ and $\mathrm{CO}_{2}$ adsorption measurements.

While $\mathrm{Kr}$ adsorption is well known to have greater accuracy in estimating porosity of small surface area materials and thin films compared to nitrogen, one can clearly see that all $\mathrm{Kr}$ isotherms and derived BET values obtained are very close to each other and smaller than the nitrogen ones (Fig. S1 and Table 1). Based on that, it is impossible to discriminate between samples. The evident discrepancy between BET values obtained from $\mathrm{Kr}$ and $\mathrm{N}_{2}$ adsorption measurements is most likely due to different saturation pressure $\mathrm{Kr}$ condenses at and bigger size of $\mathrm{Kr}$ molecule.

Among $\mathrm{N}_{2}, \mathrm{Kr}$ and $\mathrm{CO}_{2}$ only $\mathrm{CO}_{2}$ adsorption measurements brought more insight into the textural properties of studied carbons. The smaller size of $\mathrm{CO}_{2}$ molecule and the higher saturation pressure make it much better for accessing pores smaller than $1 \mathrm{~nm}$, so-called ultramicropores [32]. The $\mathrm{CO}_{2}$ adsorption isotherms along with the pore size distribution determined by 2D-NLDFT model are shown in Fig. 1. We can see that the materials present high $\mathrm{CO}_{2}$ adsorption volumes which decreases significantly particularly for temperatures higher than $1300{ }^{\circ} \mathrm{C}$. The $\mathrm{CO}_{2}$ specific area is significantly much higher compared to nitrogen one and comprised between $406 \mathrm{~m}^{2} / \mathrm{g}$ and $5 \mathrm{~m}^{2} / \mathrm{g}$ (Fig. $1 \mathrm{c}$ ). The same behavior was observed on other types of disordered carbons $[34,35]$. The pore size distribution (Fig. 1b) show a high intense peak centered around $0.45 \mathrm{~nm}$ for HC- 1000 carbon and in addition a less intense and broad peak with sizes $>1.0 \mathrm{~nm}$. The larger pore size were more accurately determined by nitrogen adsorption/desorption isotherms (Fig. S1) which reveals uniform pore with average size centered around $1.3 \mathrm{~nm}$.

Increasing the annealing temperature, the pore volume determined by NLDFT on $\mathrm{CO}_{2}$ isotherm significantly diminishes (Fig. 1b, Table S1) but their size become larger, i.e., $0.45 \mathrm{~nm}$ for HC-1000 to $0.59 \mathrm{~nm}$ for HC-1600. However, it is clear that the amount of such larger pores is very limited in the present materials as highlighted by the pore size distribution (Fig. 1b). The decrease of the pore volume is mainly associated to the microporosity closure during the thermal annealing at higher temperature. This is usually explained by the so-called "falling cards model" [36,37] which assumes that the increasing of the annealing temperature induce graphene layers organization and further lead to the microporosity collapsing and the formation of larger pores. Indeed, the organization of the hard carbons with the increase in the 

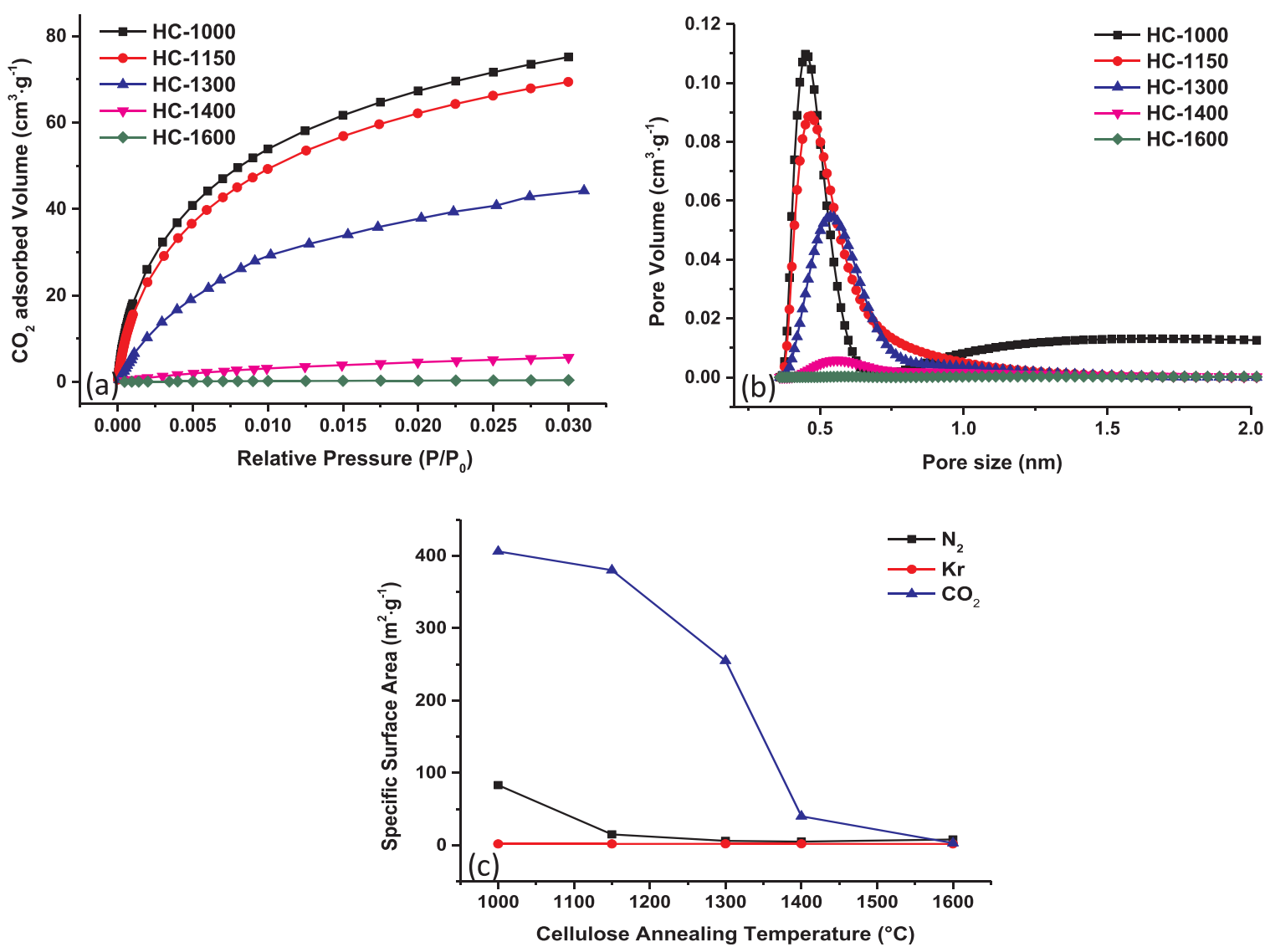

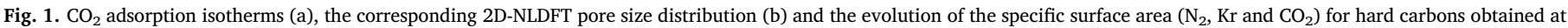
different annealing temperatures (c).

temperature is evidenced also here by the decrease of the graphene interlayer distance, $\mathrm{d}$-space (Table 1). The increase of micropore size with the increase in the annealing temperature was underlined by Small Angle X-ray Scattering (SAXS) measurements in other works as well $[14,37]$.

The evolution of the carbon specific surface area with the annealing temperature by using the three gases is shown in Fig. 1c. Except the carbon HC-1000 which has a measurable surface area by using nitrogen, the other carbons present similar surface area. When $\mathrm{Kr}$ is used, same similar low surface area is determined. On the contrary, employing $\mathrm{CO}_{2}$, high surface area is seen but this are gradually decreases with the increase of the pyrolysis temperature. This suggest that the materials are mainly ultramicroporous (pore size $<0.7 \mathrm{~nm}$ ), except the HC-1000 where some microporosity (pore size $>0.7 \mathrm{~nm}$ ) is also observed.

The type and quantities of oxygenated functional groups present on the carbon surface maybe another important parameter in the interactions with the electrolyte. Thus, the carbon surface functionality was analyzed by TPD-MS technique and the desorption rate of each gas evolved during the thermal treatment is plotted vs. temperature as shown in Fig. 2a. During the hard carbon heating, the decomposition of the functional oxygenated groups occur leading to the formation of gases such as $\mathrm{CO}$ and $\mathrm{CO}_{2}$. The type of $\mathrm{CO}_{\mathrm{x}}$ groups released and their release temperature give indication about their nature. Typically, the $\mathrm{CO}_{2}$ derives from acidic groups, i.e., carboxyl or anhydride groups while $\mathrm{CO}$ is formed by decomposition of more basic or neutral groups such as, carbonyl, phenol, ether and/or quinone groups [38].

For simplicity reasons, only one typical TPD-MS desorption curve is shown for HC-1150 carbon (Fig. 2a). We noticed an intense and large CO desorption peak comprised between 400 and $950{ }^{\circ} \mathrm{C}$ indicating the presence of a large pallet of oxygenated groups such as anhydrides, phenols, ethers and quinones $[22,39,40]$. The $\mathrm{CO}_{2}$ evolution is significantly much lower and is mainly located between 200 and $700{ }^{\circ} \mathrm{C}$ suggesting the presence of carboxyl and anhydride groups [22,39,40]. The materials are characterized also by a large peak of water release $\left(100-600{ }^{\circ} \mathrm{C}\right)$. At low temperatures this can be assigned to physisorbed water in carbon porosity while at much higher temperatures to chemisorbed water. This can be an indication of water desorbed due to the dehydration reactions of neighbour carboxyl groups leading to the formation of anhydrides which decomposes at higher temperature concomitantly to both $\mathrm{CO}$ and $\mathrm{CO}_{2}$ gases. Furthermore, a peak of hydrogen is observed at high temperature $\left(>800{ }^{\circ} \mathrm{C}\right)$ which is typical for the cleavage of the $\mathrm{C}-\mathrm{H}$ bonds and carbon structural organization.

The integration of $\mathrm{CO}$ and $\mathrm{CO}_{2}$ desorption peaks allows to quantify the amounts of the oxygenated groups released from the carbon surface as seen gather in Table 1. According to Table 1, the amount of CO evolved is higher than $\mathrm{CO}_{2}$ in good agreement with the desorption profiles intensity. The total amount of oxygen groups evolution $\left(\mathrm{CO}_{\mathrm{x}}\right.$ : $\mathrm{CO}+\mathrm{CO}_{2}$ groups) with the annealing temperature of cellulose is presented in Fig. $2 \mathrm{~b}$ and a decrease of the amount of $\mathrm{CO}_{\mathrm{x}}$ groups is seen with the increase of the pyrolysis temperature. The same tendency is observed for water and hydrogen gases.

After removing the oxygen functional groups from the carbon surface by the in-situ TPD-MS treatment up to $950{ }^{\circ} \mathrm{C}$ under vacuum, the surface defect concentration was determined in terms of active surface area by exposing the carbon to oxygen at $300{ }^{\circ} \mathrm{C}$ overnight. Oxygen functionalities are formed and a subsequent TPD-MS analysis allows to quantify them and to calculate the ASA. The ASA values obtained for all carbons are listed in Table 1 while its evolution with the temperature of cellulose annealing temperature shown in Fig. 2 b.

The ASA decreases from $44 \mathrm{~m}^{2} \mathrm{~g}^{-1}$ for HC- 1000 to $1 \mathrm{~m}^{2} \mathrm{~g}^{-1}$ for HC1600 , therefore, the amount of defects diminishes with the increase of 

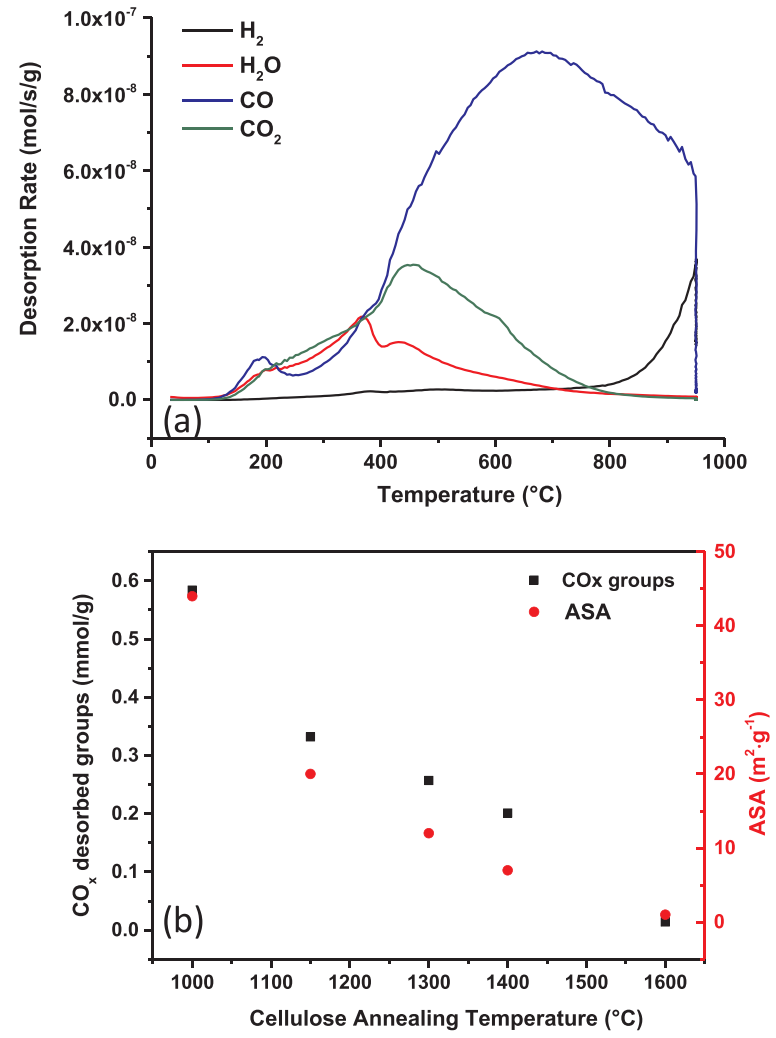

Fig. 2. Representative TPD-MS thermal desorption profiles for HC-1150 carbon (a) total desorbed quantities of oxygen functional groups, COx and the active surface area, ASA recorded for all carbon materials derived from cellulose pyrolysed at different temperatures (b).

the annealing temperature similarly as the amount of oxygen groups. This maybe understood by the formation of edge defects, vacancies, dangling bonds during the pyrolysis treatment and once exposed to air such defects are highly reactive towards oxygen from air and induce the formation of oxygen groups. It can be supposed that the functional groups are anchored on carbon defects. This is coherent with the fact that the amount of functional groups and the amount of defects are varying in the same manner with the annealing temperature.

The increase in the short-range ordering of the carbon with the temperature was proven as well by the decrease of the interlayer spacing $d_{(002)}$ from 3.88 to $3.72 \AA$ (Table 1 ), as previously determined by XRD analysis [14]. The high resolution transmission electron microscopy (HRTEM) images (Fig. S2, Supporting Information's) performed on the lowest and highest temperature treated materials, i.e., HC-1000 and HC-1600 show the increase of ordered structure containing graphitic domains with the increase of the temperature. More staked graphene layers are observed in line with the selected area electron diffraction (SAED) analysis demonstrating more defined diffractions rings (Fig. S2, Supporting information's).

As previously demonstrated for $\mathrm{Li}$ ion batteries, ASA differences may induce a modification in carbon reactivity towards the electrolyte and direct the electrolyte decompositions and further the formation of SEI layer $[20,41]$. In the case of Na-ion batteries, the influence of ASA on electrochemical performances was not yet evaluated.

Fig. S3 (Supporting information's), shows the first charge/discharge cycle for all hard carbons and we notice that the first reduction capacity was around $360 \mathrm{mAh} / \mathrm{g}$ for all materials (Table S1, Supporting information's). The evolution of the irreversible, reversible, slope and plateau capacities with the pyrolysis temperature of cellulose is provided in Fig. S4 (Supporting information's). It can be observed that the irreversible capacity and the sloping capacity follow the same trend, i.e., decrease of the capacity with the increase of the cellulose annealing temperature while for the reversible and plateau capacities an opposite behavior is seen. To go more in details about the key parameters behind these trends one must be considered that during the thermal pyrolysis several events occurs giving rise to modifications of several carbon characteristics. To recall, the specific surface area, the amount of oxygen surface groups, the active sites (amount of defects) and the dspace decreases with the increase of the pyrolysis temperature. Thanking into consideration the similar variation of these characteristics with the temperature, the main difficulty and challenge here is to highlight the main important carbon characteristic influencing the electrochemical performances. For simplicity reasons, the slope capacity and plateau capacity which are subject of controversial mechanisms explanations in the literature will be discussed in more details in relation with carbon characteristics.

Regarding the sloping and the irreversible capacity, a notable dependence on the pyrolysis temperature is observed, i.e., decrease of the capacity with the increase in the annealing temperature which translates as well in coulombic efficiency variation with the temperature, i.e., increase from $72 \%$ for $\mathrm{HC}-1000$ to $84 \%$ for $\mathrm{HC}-1600{ }^{\circ} \mathrm{C}$. The irreversible capacity is closely related to the formation of the solid electrolyte interphase (SEI) due to the interaction of carbon surface with the electrolyte. Several works pointed out that the irreversible capacity can be correlated to the carbon accessible surface area quantified as BET surface area with nitrogen adsorbent $[14,42,43]$. Generally, the decrease of the BET surface area induces a decrease of the irreversible capacity. However, no correlation concerning the surface area of ultramicropores (pores $<0.7 \mathrm{~nm}$ ) was established up to now. We determined the surface area of such small pores by $\mathrm{CO}_{2}$ adsorption and interestingly we can see that the sloping capacity is increasing with the increase of specific surface area (Fig. 3a). We noticed that the same trend as for nitrogen BET surface area is found, suggesting that small pores $(<0.7 \mathrm{~nm})$ are as well involved in the $\mathrm{Na}^{+}$storage mechanism which was not considered before. The same trend as for the sloping capacity is seen for the irreversible capacity (Fig. S5, Supporting information) while the plateau capacity show an opposite behavior, i.e., decrease of the capacity with the increase of specific surface area.

Other factors than porosity affecting the capacities are the carbon surface chemistry (oxygen functional groups) and the amount of defects. Although the oxygen functional groups amount may be assessed by other techniques than TPD-MS, i.e, XPS or Boehm titration, the active sites may be assessed precisely only by oxygen chimisorption followed by TPD-MS, explaining the lack of studies measuring such parameter on carbons. Fig. $3 \mathrm{~b}$ links the sloping capacity and the amount of oxygen functional groups and a correlation maybe established, i.e., the higher the amount of oxygenated groups, the higher the sloping is obtained. The same trend is observed for the ASA as well. Therefore, the amount of functional groups and of defects induces similar effect on the sloping capacity.

In the case of plateau capacity, an opposite behavior than the sloping capacity was observed, i.e., the higher the amount of oxygenated groups and defects the smaller the plateau capacity is obtained (Fig. S5b, Supporting information).

In order to discriminate between the effect of oxygen surface groups and the ASA, the HC-1400 carbon was oxidized by nitric acid in order to increase the amount of surface groups (HC-1400ox) [38]. A part of the obtained oxidized material (HC-1400ox) was annealed further in hydrogen up to $900{ }^{\circ} \mathrm{C}$ to remove the formed surface groups (HC1400red). This kind of treatment was proven to be efficient to remove oxygenated groups from graphitic materials while keeping rather similar ASA [22]. A schematic representation of modification procedure is provided in Fig. S6, Supporting information. The performed oxidation and the reduction treatments have a great impact in the modification of surface chemistry, ASA but also specific surface area (Table 2).

The oxidation of HC-1400 material induces as expected a significant increase in the amount of functional groups and in addition an increase in the porosity and active surface area on the obtained HC-1400ox. 

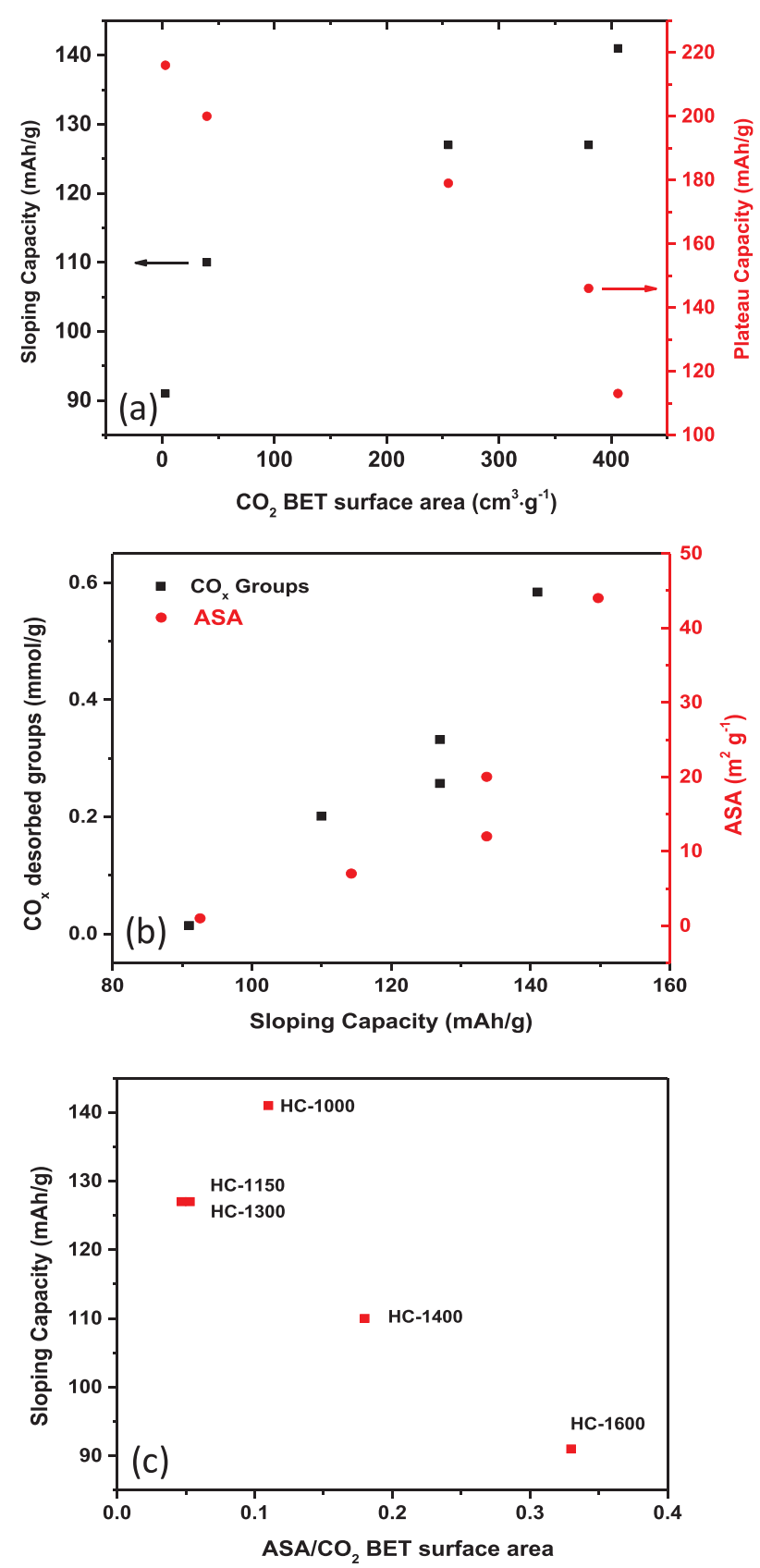

Fig. 3. (a) Correlation between the sloping capacity and plateau reversible capacity with the $\mathrm{CO}_{2}$ surface area; (b) correlation between carbon sloping capacity and the total amounts of $\mathrm{CO}_{\mathrm{x}}$ groups desorbed during TPD measurements and the active surface area (c) and correlation between carbon sloping capacity and the ratio ASA/BET $\mathrm{CO}_{2}$.

When the later one is subject of hydrogen reduction (HC-1400red), most of functional groups are removed, the $\mathrm{CO}_{\mathrm{x}}$ quantities being similar to the pristine HC-1400, as highlighted in Table 2. In the same time, the ASA decreases compared to HC-1400ox $\left(31 \mathrm{~m}^{2} \mathrm{~g}^{-1}\right.$ for HC-1400ox vs. $21 \mathrm{~m}^{2} \mathrm{~g}^{-1}$ for HC-1400red) but still remains significantly higher than

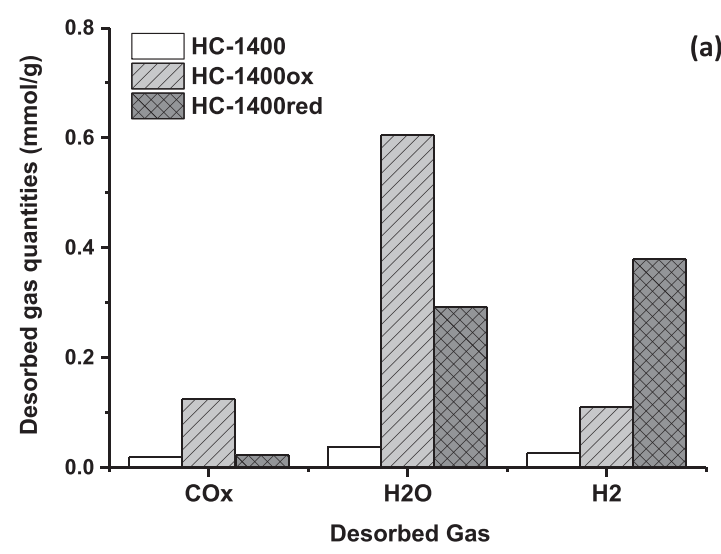

(a)

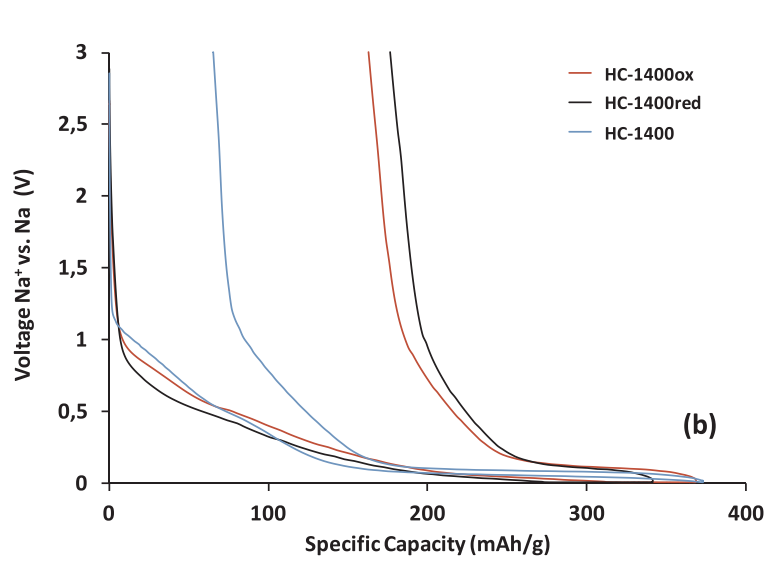

Fig. 4. (a) Desorbed gas quantities $\left(\mathrm{CO}_{\mathrm{x}}, \mathrm{H}_{2} \mathrm{O}\right.$ and $\left.\mathrm{H}_{2}\right)$ as determined by TPD-MS analyses for HC-1400 carbons; (b) First charge-discharge curve of hard carbons cycled at a $\mathrm{C} / 10$ rate where $C=37.2 \mathrm{~mA} / \mathrm{g}$ between $10 \mathrm{mV}$ and $3 \mathrm{~V}$ of modified hard carbons tested against sodium metal at $37.2 \mathrm{~mA} / \mathrm{g}$ with $1 \mathrm{M} \mathrm{NaPF}_{6}$ in EC: DMC (1:1) between $50 \mathrm{mV}$ and $3 \mathrm{~V}$.

pristine HC-1400 $\left(6.8 \mathrm{~m}^{2} \mathrm{~g}^{-1}\right)$. As for the porosity, the reduction treatment of HC-1400ox has only limited effect.

Considering that the new obtained materials present higher surface area and ASA than HC-1400 and also higher amount of functional groups in the case of HC-1400ox, this triggers as expected an increase in the irreversible capacity from $65 \mathrm{mAh} / \mathrm{g}$ for pristine HC-1400 to $170 \mathrm{mAh} / \mathrm{g}$ for modified carbons, HC-1400ox and HC-1400red, respectively (Table 2). The columbic efficiency decreases as well from $82.7 \%$ (HC-1400) to $48.2 \%$ (HC-1400red) suggesting that the electrolyte is consumed irreversibly.

If we compare in more details the HC-1400ox and HC-1400red, we can noticed that the specific surface areas determined by nitrogen and $\mathrm{CO}_{2}$ are slightly higher for HC-1400red. In addition, a significant difference is observed in the amount of oxygen groups $\left(\mathrm{CO}_{\mathrm{x}}\right)$, the HC1400 ox present $5 \mathrm{x}$ higher amount of surface groups $(1.25 \mathrm{mmol} / \mathrm{g})$ compared to HC-1400red $(0.23 \mathrm{mmol} / \mathrm{g})$. With the increase of the amount of oxygen groups (HC-1400ox), the amount of desorbed physisorbed water is increasing also due to the improvement of the hydrophilic behavior (Fig. 4a). The porosity also influences the amount of

Table 2

Textural, surface chemistry, active surface area and electrochemical performances of HC-1400, HC-1400ox and HC-1400red.

\begin{tabular}{|c|c|c|c|c|c|c|c|}
\hline Materials & BET $\mathrm{N}_{2} \mathrm{~m}^{2} \mathrm{~g}^{-1}$ & $\begin{array}{l}\text { BET } \mathrm{CO}_{2} \\
\mathrm{~m}^{2} \mathrm{~g}^{-1}\end{array}$ & $\mathrm{COx} \mathrm{mmol} / \mathrm{g}$ & ASA $\mathrm{m}^{2} \mathrm{~g}^{-1}$ & $\begin{array}{l}1^{\text {st }} \text { insertion capacity } \\
\mathrm{mAh} / \mathrm{g}\end{array}$ & $\begin{array}{l}1^{\text {st }} \text { irreversible capacity mAh/ } \\
\mathrm{g}\end{array}$ & $1^{\text {st }}$ coulombic efficiency $\%$ \\
\hline HC-1400 & 5 & 40 & 0.20 & 6.8 & 375 & 65 & 82.7 \\
\hline HC-1400ox & 271 & 163 & 1.25 & 31 & 368 & 162 & 55.9 \\
\hline HC-1400red & 318 & 221 & 0.23 & 21 & 342 & 177 & 48.2 \\
\hline
\end{tabular}


adsorbed water and this is clearly seen by comparing HC-1400 and HC1400red. The later one has rather low amounts of oxygen groups but desorbs higher water amounts (Fig. 4a) which is related to its higher porosity compared to HC-1400 (Table 2). Hence, both surface chemistry and porosity influence the amounts of water adsorbed on carbon. This is an important issue to take into account; on one hand, the interactions with the electrolyte can be modified giving rise to undesired side reactions, and on the other hand, from more practical point of view, such electrodes containing water in their porosity must be outggased at temperatures up to $200{ }^{\circ} \mathrm{C}$ (temperature where the water release is finished). Another consequence of surface modification of HC-1400 by oxidation and reduction is the formation of C-H bonds, the amounts of hydrogen released increasing for the HC-1400ox and more significantly for HC-1400red which was hydrogen treated (Fig. 4a).

Concerning the ASA values, the HC-1400ox have an ASA of $31 \mathrm{~m}^{2} / \mathrm{g}$ while the thermal annealing under hydrogen decreases the ASA to $21 \mathrm{~m}^{2} / \mathrm{g}$ (HC-1400red). Therefore, the main important difference between the two materials is the high amount of surface groups of HC1400ox compared to HC-1400red. It is interesting to notice that such increase in oxygen functional groups does not induce significant difference in the shape of charge/discharge curves and the irreversible capacity (Fig. 4b and Table 2), suggesting that the amount of surface groups is not the main parameter influencing the irreversible capacity and the sloping region capacity. The slightly higher irreversible capacity for HC-1400red may be linked to its higher porosity (Table 2). Another reason may be the higher amounts of $\mathrm{C}-\mathrm{H}$ bonding. Such bonds proved to be able to link with the $\mathrm{Na}^{+}$and $\mathrm{Li}^{+}$inducing the formation of C-Na or C-Li bonds [44] and also to favor the graphite exfoliation in EC-based electrolytes [20].

Regarding the plateau capacities of HC-1400ox and HC-1400red, it can be seen that they are decreasing compared to pristine HC-1400 (Fig. 4b). This may be explained on one hand by the increase of the specific surface area but also of active surface area ASA (Table 2).

Notwithstanding the ASA is the most pertinent parameter influencing the capacity, still the porosity must be taken into account. In such case, it is useful to calculate the density of active sites as a ratio between ASA and the BET $\mathrm{CO}_{2}$ surface area [22]. In Fig. 3c, the correlation between the density of active sites and the slopping capacity is shown. It can be seen that the sloping capacity diminish rather linearly with the increase of the density of active sites suggesting the main importance of the defects in the sloping region. The HC-1000 material deviates from the linear shape of the correlation and this may be due to the fact that in such case the material contains not only ultramicropores detectable by $\mathrm{CO}_{2}$ but also larger pores which were detected by nitrogen (Fig. S1a, Supporting information) and not taken into account here.

Gathering most of the results in Fig. 5, one can see that the carbon characteristics (microporosity, oxygen surface groups, active surface area and $\mathrm{d}_{002}$ space) are decreasing with the increase of the pyrolysis temperature. Interestingly, the sloping capacity is decreasing almost linearly in the same way while the plateau capacity varies in an opposite way. To further discuss the founding of this work in relation to previous works one must consider firstly the porosity of hard carbons. The gas adsorption measurements performed in this work highlighted that the hard carbon is composed at low temperature of micropores and in addition of ultramicropores, measureable only with $\mathrm{CO}_{2}$ gas. Such small pores are usually not measured and not considered in most of the works when discussing the performances of hard carbon. A great quantity of micropores/ultramicropores are formed at low pyrolysis temperature $\left(<1400{ }^{\circ} \mathrm{C}\right)$ while the plateau capacity is low (Fig. 3a). By increasing the pyrolysis temperature $\left(>1400{ }^{\circ} \mathrm{C}\right)$, all the pores are removed while the plateau capacity increases (Fig. 3a). We establish a relationship between the plateau capacity and the surface area of ultramicropores, i.e., increase of plateau capacity with the decrease of the surface area (Fig. 5). This trend is in contradiction with the classical proposed mechanisms of Na-storage where the plateau capacity is often related to the insertion/adsorption of $\mathrm{Na}$ in the carbon porosity. At this
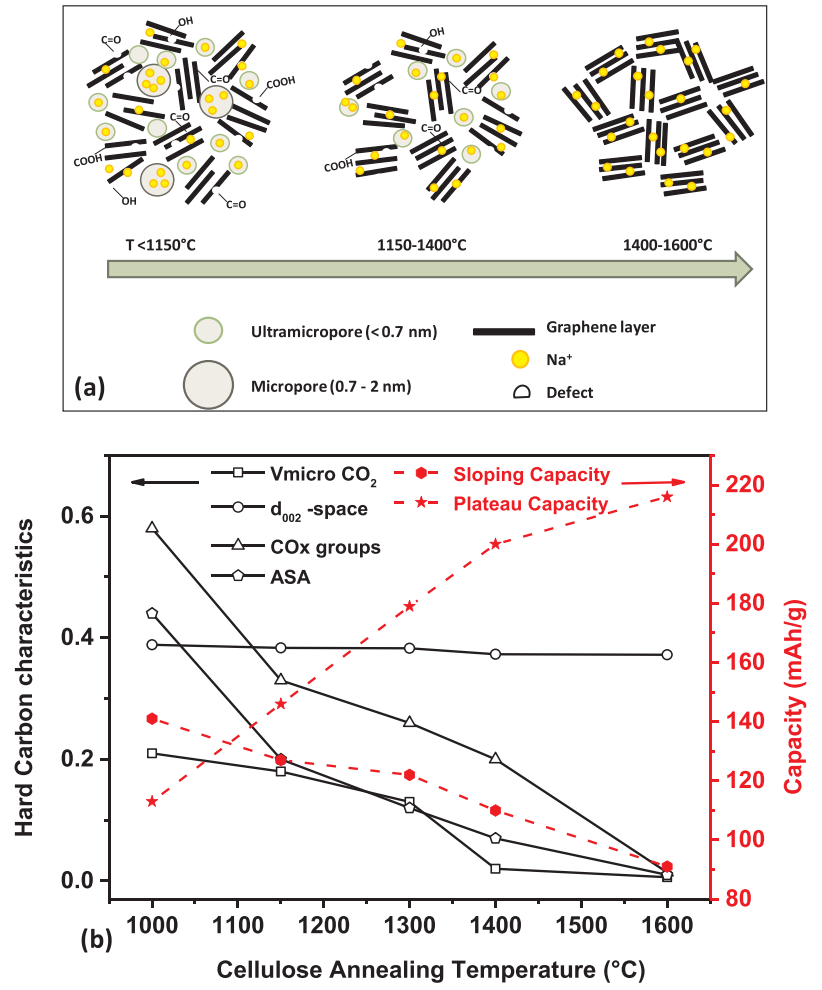

Fig. 5. Schematic representation of the evolution of hard carbon microstructure with the annealing temperature of cellulose along with sodium insertion (a) and evolution of hard carbons characteristics $\left(\mathrm{V}_{\text {micro }} \mathrm{CO}_{2}\left(\mathrm{~cm}^{3} / \mathrm{g}\right) ; \mathrm{d}_{002}\right.$-space $(\mathrm{nm})$; $\mathrm{COx}$ groups $(\mathrm{mmol} / \mathrm{g})$ and ASA $\left(10^{2} \mathrm{~m}^{2} / \mathrm{g}\right)$ and sloping and plateau capacities vs. the annealing temperature of cellulose.

stage the materials have no porosity, therefore, sodium filling mechanism in the nanopores is questionable. Our results join the results of Cao et al. [10] who firstly proposed the assigning of the plateau region to the insertion/extraction of $\mathrm{Na}^{+}$between the carbon layers. They performed theoretical calculations on the energy required for Na-ion insertion into carbon as a function of carbon interlayer distance, and predicted an interlayer distance of $\sim 0.37 \AA$ to be suitable to enable Naion insertion between the carbon layers.

In the same line, Ding et al. [11] ascribed the plateau region of a pyrolytic carbon to insertion of Na between the graphitic layers instead of micropores. Qiu et al. [45] calculated the theoretical plateau capacity of cellulose-derived hard carbons considering Na saturated filling in the micropores and they observed a linear relationship with the microporous volume. However, the comparison with the experimental values showed a rather opposite behavior demonstrating once again that the micropore filling mechanism cannot explain the evolution of plateau capacity. This was further confirmed by using micro/mesoporous carbons which exhibited only a single sloping region, therefore absence of a plateau region.

In addition to micropores, the hard carbons present at low temperature oxygen functional groups (carboxyl, lactones, ethers, quinones) and defects (edge defects, vacancies, staking faults...). As determined by TPD-MS, the amount of oxygen functional groups and the amount of active sites (defects) are decreasing both with the increase in the pyrolysis temperature. We established as well that the sloping capacity decrease with the decrease of the functional groups and amount of defects (Fig. 5). Moreover, controlled surface oxidation/reduction on HC-1400 allowed discriminating between the importance of functional groups and defects in the storage mechanism. The results showed that the functional groups are significantly less important in the storage mechanisms compared with defects. Similar dependence was found in our previous studies performed on graphite materials in Li-ion batteries 
[20].

Other recent works pointed out as well the $\mathrm{Na}^{+}$storage in the sloping region occurs via interactions of sodium with the carbon edge defects [8,13,24,25,33]. Particularly, Bommier et al. [13] found a linear relationship between the carbon defects estimated by $\mathrm{I}_{\mathrm{D}} / \mathrm{I}_{\mathrm{G}}$ ratio from Raman spectroscopy and the sloping capacity. This trend is in well agreement with the correlation we established herein between the active surface area and the sloping capacity. Theoretical studies were conducted as well $[24,25]$ on graphenes having a disordered structure in which mainly mono- vacancy, di-vacancy and Stone-Wales defects were considered. These studies come to the same conclusion that the sloping part is indeed related to the storage of $\mathrm{Na}$ in the carbon defects. The strong ionic binding energy between the $\mathrm{Na}^{+}$adsorption and the defects may effectively overcome the van der Waals interactions between the graphenes planes and make possible the sodiation. Local probe in-situ and ex-situ analyses such as ${ }^{23} \mathrm{Na}$ solid-state NMR and pair distribution function indicated in the sloping region a mechanism where $\mathrm{Na}^{+}$is first adsorbing on pore surface and defects. Such defects would favor also larger graphene interplanar distances and therefore $\mathrm{Na}^{+}$insertion. At higher voltages (plateau region), rather Na quasimetallic species are formed [46]. Such scenario based on adsorption of Na-ions on carbon pores and defects in the sloping region and their further intercalation with the formation of $\mathrm{NaC}_{\mathrm{x}}$ compounds in the plateau region was recently proposed by Qiu et al. [45].

Therefore, based on the results obtained herein we can conclude that the sloping region is related to the $\mathrm{Na}^{+}$storage/adsorption in the carbon porosity and carbon defects and in less extent to disordered pseudo-graphitic domains. The plateau region could be ascribed to $\mathrm{Na}^{+}$ intercalation between the graphitic carbon planes. This is sustained by the increase in sloping capacity with the removal of pores and defects and the opposite behavior with the plateau capacity (Fig. 5). These results provide a complete overall picture of the Na-ion storage mechanism in the sloping and plateau regions and their evolution with the main hard carbon characteristics (porosity, surface functionalities, defects and structure) over a large range of annealing temperatures and is summarized is Fig. 5.

\section{Conclusions}

A series of hard carbon were prepared via the pyrolysis of cellulose at temperatures ranged between 1000 and $1600{ }^{\circ} \mathrm{C}$ in order to systematically evaluate the porosity, surface chemistry and defects in relation with the $\mathrm{Na}$ storage mechanism in the sloping and plateau regions.

Several gases were used in order to properly asses the carbon porosity. Except the carbon treated at low temperature (HC-1000) which shows a measureable BET surface area, the other materials exhibit low surface areas when nitrogen is used as probe molecule, in agreement with many works. On the contrary, when $\mathrm{CO}_{2}$ is used, high surface areas is evidenced which are related to the presence ultramicropores (pore size $<0.7 \mathrm{~nm}$ ). The porosity was found to decrease with the increase of the temperature and for high temperatures $\left(>1400{ }^{\circ} \mathrm{C}\right)$ no porosity was detected in the materials neither by nitrogen or $\mathrm{CO}_{2}$ adsorption. The plateau capacity was found to increase with the decrease of the porosity which clearly disqualifies the classical mechanism of its attribution to the adsorption of $\mathrm{Na}^{+}$in the nanopores. We assigned the plateau capacity rather to the insertion of $\mathrm{Na}^{+}$in the graphitic nanodomains.

The carbon surface functionalities and active surface area related to carbon edge defects were quantitatively determined by TPD-MS and a decrease in their amounts with the increase of the temperature was demonstrated. The sloping region was found to decrease with the decrease of the amount of active sites; therefore, the sloping region ascribed to the insertion of $\mathrm{Na}^{+}$between the graphene layers is strongly influenced by the carbon defects.

In summary, we found that the sloping region is related to the $\mathrm{Na}$ ions interaction with the carbon edge defects and their adsorption into porosity and in less extent to its insertion into the carbon pseudo-graphitic nanodomains. The plateau region was attributed to the insertion of $\mathrm{Na}^{+}$into the graphitic structure, the pore nanofilling mechanism being excluded.

\section{Acknowledgements}

The authors acknowledge financial support of this work through the European Union's Horizon 2020 Program (project NAIADES, call: LCE10-2014, Contract no. 646433) and the RS2E network. The French General Directorate for Armament (DGA) is acknowledged for cofunding of the Ph.D. thesis of Virginie Simone. The authors thank Dr. Loic Vidal for performing the HRTEM/SAED. Dr. Joseph Denzer is acknowledged for the valuable discussions concerning the TPD-MS analysis.

\section{Competing financial interests}

The authors declare no competing financial interest.

\section{Appendix A. Supporting information}

Supplementary data associated with this article can be found in the online version at http://dx.doi.org/10.1016/j.nanoen.2017.12.013.

\section{References}

[1] E. Irisarri, A. Ponroucha, M. Palacin, Review-hard carbon negative electrode materials for sodium-ion batteries, J. Electrochem. Soc. 162 (2015) A2476-A2482.

[2] W. Luo, F. Shen, C. Bommier, H. Zhu, X. Ji, L. Hu, Na-ion battery anodes: materials and electrochemistry, Acc. Chem. Res. 16 (2016) 231-240.

[3] H. Kang, Y. Liu, K. Cao, Y. Zhao, L. Jiao, Y. Wang, H. Yuan, Update on anode materials for Na-ion batteries, J. Mater. Chem. A 3 (2015) 17899-17913.

[4] J. Gorka, C. Vix-Guterl, C. Matei-Ghimbeu, Recent progress in design of biomassderived hard carbons for sodium ion batteries, C 2, vol. 24, 2016, pp. 1-17.

[5] M. Dahbi, N. Yabuuchi, K. Kubota, K. Tokiwa, S. Komaba, Negative electrodes for Na-ion batteries, Phys. Chem. Chem. Phys. 16 (2014) 15007-15028.

[6] G. Hasegawa, N. Kanamori, J.-I. Ozaki, K. Nakanishi, T. Abe, Hard carbon anodes for Na-ion batteries: toward practical use, ChemElectroChem 2 (2015) 1917-1920.

[7] G. Zou, Z. Huang, G. Zhao, S. Li, H. Hou, X. Qiu, X. Ji, Evaluating the storage behaviour of superior low-cost anode material from biomass for high-rate sodiumion batteries, J. Electrochem. Soc. 164 (2017) A1431-A1437.

[8] E. Lotfabad, P. Kalisvaart, A. Kohandehghan, D. Karpuzov, D. Mitlin, Origin of non SEI setalted coloumbic efficiency loss in carbons tested against Na and Li, J. Mater. Chem. A 2 (2014) 19685.

[9] D. Stevens, J. Dahn, High capacity anode materials for rechargeable sodium-ion batteries, J. Electrochem. Soc. 147 (2000) 1271-1273.

[10] Y. Cao, L. Xiao, M. Sushko, W. Wang, B. Schwenzer, J. Xiao, Z. Nie, L. Saraf, Z. Yang, J. Liu, Sodium ion insertion in hollow carbon nanowires for battery applications, Nano Lett. 12 (2012) 3783-3787.

[11] J. Ding, H. Wang, L. Zhi, A. Kohandehghan, K. Cui, Z. Xu, B. Zahiri, X. Tan, E. Lotfabad, B. Olse, D. Mitlin, Carbon nanosheet frameworks derived from peat moss as high performance sodium ion battery anodes, ACS Nano 7 (2013) 11004-11015.

[12] E. Lotfabad, J. Ding, K. Cui, A. Kohandehghan, P. Kalisvaart, M. Hazelton, D. Mitlin, High-density sodium and lithium ion battery anodes from banana peels, ASC Nano 8 (2014) 7115-7129.

[13] C. Bommier, T. Surta, M. Dolgos, X. Ji, New mechanistic insights on Na-ion storage in nongraphitisable carbon, Nano Lett. 15 (2015) 5888-5892.

[14] V. Simone, A. Boulineau, A. de Geyer, D. Rouchon, L. Simonin, S. Martinet, Hard carbon derived from cellulose as anode for sodium ion batteries: dependence of electrochemical properties on structure, J. Energy Chem. 25 (2016) 761-768.

[15] P. Ehrburger, N. Pusset, P. Dziedzinl, Active surface area of microporous carbons, Carbon 30 (1992) 1105-1109.

[16] P. Ehrburger, F. Louys, J. Lahaye, The concept of active sites applied to the study of carbon reactivity, Carbon 27 (2017) 389-393.

[17] N.R. Laine, F.J. Vastola, J.P.L. Walker, The importance of active surface area in the carbon-oxygen reaction, J. Phys. Chem. 67 (1963) 2030-2034.

[18] C. Vix-Guterl, M. Couzi, J. Dentzer, M. Trinquecoste, P. Delhaes, Surface characterisations of carbon multiwall nanotubes: comparaison between surface active sites and Raman spectroscopy, J. Phys. Chem. B 108 (2004) 19361-19367.

[19] F. Beguin, F. Chevallier, C. Vix-Guterl, S. Saadallah, V. Bertagna, J.N. Rouzaud, E. Frackowiak, Correlation of the irreversible lithium capacity with the active surface area of modified carbons, Carbon 43 (2005) 2160-2167.

[20] Ph Bernardo, J. Dentzer, R. Gadiou, W. Märkle, D. Goers, P. Novák, M.E. Spahr, C. Vix-Guterl, Influence of graphite surface properties on the first electrochemical 
lithium intercalation, Carbon 49 (2011) 4867-4876.

[21] C. Matei Ghimbeu, C. Decaux, P. Brender, M. Dahbi, D. Lemordant, E. RaymundoPinero, M. Anouti, F. Beguin, C. Vix-Guterl, Influence of graphite characteristics on the electrochemical performance in alkylcarbonate LiTFSI electrolyte for Li-ion capacitors and Li-ion batteries, J. Electrochem. Soc. 160 (2013) A1907-A1915.

[22] G. Moussa, C. Matei Ghimbeu, P.-L. Taberna, P. Simon, C. Vix-Guterl, Relationship between the carbon nano-onions (CNOs) surface chemistry/defects and their capacitance in aqueous and organic electrolytes, Carbon 105 (2016) 268-277.

[23] J. Lahaye, The chemistry of carbon surfaces, Fuel 77 (1998) 543-547.

[24] D. Datta, J. Li, V. Shenoy, Defective graphene as a high-capacity anode material for Na- and Ca-ion batteries, ACS Appl. Mater. Interfaces 6 (2014) 1788-1795.

[25] P.-C. Tsai, S.-C. Chung, S.-K. Lin, A. Yamada, Ab initio study of sodium intercalation into disordered carbon, J. Mater. Chem. A 3 (2015) 9763-9768.

[26] P. Wang, B. Qiao, Y. Du, Y. Li, X. Zhou, Z. Dai, Fluorine-doped carbon particles derived from Lotus Petioles as high-performance anode materials for sodium-ion batteries, J. Phys. Chem. C 119 (2015) 21336-21344.

[27] Z. Wu, F.-L. Meng, D.-L. Ma, X.-L. Huang, L.-M. Wang, X.-B. Zhang, Nitrogen-doped porous carbon nanosheets as low-cost,high-performance anode material for sodiumion batteries Heng-guo Wang, ChemSusChem 6 (2013) 56-60.

[28] B. Ruan, J. Wang, D. Shi, Y. Xu, S. Chou, H. Liu, J. Wang, A phosphorus/N-doped carbon nanofiber composite as an anode material for sodium-ion batteries, J. Mater. Chem. 3 (2015) 19011-19017.

[29] H. Tang, D. Yan, T. Lu, L. Pan, Sulfur-doped carbon spheres with hierarchical micro/mesopores as anode materials for sodium-ion batteries, Electrochem. Acta 214 (2017) 63-72.

[30] J. Jagiello, J. Olivier, Carbon slit pore model incorporating surface energetical heterogeneity and geometrical corrugation, Adsorption 19 (2013) 777-783.

[31] J. Jagiello, J. Olivier, 2D-NLDFT adsorption models for carbon slit-shaped pores with surface energetical heterogeneity and geometrical corrugation, Carbon 55 (2013) 70-80.

[32] K. Cychosz, R. Guillet-Nicolas, J. Garcia-Martinez, M. Thommes, Recent avances in the textural characterization of hierarchically structured nanoporous materials, Chem. Soc. Rev. 46 (2017) 389-414.

[33] Y. Li, Y.-S. Hu, M. Titirici, C. Liquan, X. Huang, Hard carbon microtubes made from renewable cotton as high-performance anode material for sodium-ion batteries, Adv. Energy Mater. 1600659 (2016) 1-9.
[34] F. Béguin, F. Chevallier, C. Vix, J. Rouzaud, E. Frackowiak, A better understanding of the irreversible lithium insertion mechanisms in disordered carbons, J. Phys. Chem. Solids 65 (2004) 211-217.

[35] B. Zhang, C. Matei Ghimbeu, C. Laberty, C. Vix-Guterl, J. Tarascon, Correlation between microstructure and Na storage behaviour in hard carbon, Adv. Energy. Mater. 1501588 (2016) 1-9.

[36] J. Dahn, W. Xing, Y. Gao, The "falling cards model" for the structure of microporous carbons, Carbon 35 (1997) 825-830.

[37] E. Buiel, A. George, J. Dahn, Model of micropore closure in hard carbon prepared from sucrose, Carbon 37 (1999) 1399-1407.

[38] J.L. Figueiredo, M.F.R. Pereira, M.M.A. Freitas, J.J.M. Orfao, Modification of the surface chemistry of activated carbons, Carbon 37 (1999) 1379-1389.

[39] C. Matei Ghimbeu, R. Gadiou, J. Dentzer, D. Schwartz, C. Vix-Guterl, Influence of surface chemistry on the adsorption of oxygenated hydrocarbons on activated carbons, Langmuir 26 (2010) 18824-18833.

[40] V. Ruiz, C. Blanco, E. Raymundo-Piñero, V. Khomenko, F. Beguin, R. Santamaria, Effects of thermal treatment of activated carbon on the electrochemical behaviour in supercapacitors, Electrochim. Acta 52 (2007) 4969-4973.

[41] S.H. Ng, C. Vix-Guterl, Ph Bernardo, N. Tran, J. Ufheil, H. Buqa, J. Dentzer, R. Gadiou, M.E. Spahr, D. Goers, P. Novák, Correlations between surface properties of graphite and the first cycle specific charge loss in lithium-ion batteries, Carbon 47 (2009) 705-712.

[42] C. Bommier, W. Luo, W.-Y. Gao, A. Greaney, S. Ma, X. Ji, Predicting capacity of hard carbon anodes in sodium-ion batteries using porosity measurements, Carbon 76 (2014) 165-174.

[43] A. Ponrouch, A. Goni, R. Palacin, High capacity hard carbon anodes for sodium ion batteries in additive free electrolyte, Electrochem. Commun. 27 (2013) 85-88.

[44] D. Stevens, J.R. Dahn, The mechanisms of lithium and sodium insersion in carbon materials, J. Electrochem. Soc. 148 (2001) A803-A811.

[45] S. Qiu, L. Xiao, M. Sushko, K. Han, Y. Shao, M. Yan, X. Liang, L. Mai, J. Feng, Y. Cao, X. Ai, H. Yang, J. Liu, Manipulating adsorption-insertion mechanisms in nanostructured carbon materials for high-efficiency sodium ion storage, Adv. Energy Mater. 7 (2017) 1700403.

[46] J. Stratford, P. Allan, O. Pecher, P. Chater, C. Grey, Mechanistic insights into sodium storage in hard carbon anodes using local probes, ChemComm 52 (2016) $12340-12433$. 